\title{
Prediction of the Solar Radiation Map on Algeria by Latitude and Longitude Coordinates
}

\author{
Foued Chabane ${ }^{1,2^{*}}$, Ali Arif ${ }^{3}$, Said Benramache ${ }^{4}$ \\ ${ }^{1}$ Mechanical Department, Faculty of Technology, University of Biskra, 07000, Algeria \\ ${ }^{2}$ LGM Laboratoire de genie mécanique Biskra, University of Biskra, 07000, Algeria \\ ${ }^{3}$ Electrical Department, Faculty of Technology, University of Biskra, 07000, Algeria \\ ${ }^{4}$ Department of physic, University of Biskra, Biskra, Algeria
}

Corresponding Author Email: fouedmeca@hotmail.fr

https://doi.org/10.18280/ti-ijes.642-413

Received: 26 February 2020

Accepted: 9 May 2020

\section{Keywords:}

prediction, solar radiation, map, latitude, longitude

\begin{abstract}
Aims the study is how to create the model of the solar radiation as a function to coordinates of latitude and longitude of the location point for determined every points on the map of Algeria. This solar radiation varying according to type of the area, because the Algeria area changing from the rock, a vegetarian environment and desert area. Our model gives a good away for all area of the Algeria by average solar radiation with residual $\mathrm{R}^{2}=0.981$ about latitude and 0.866 of longitude.

The model it's good for help most researcher to calculate all points in the Algeria ground such as numerical study.
\end{abstract}

\section{INTRODUCTION}

Algeria is ranked among the five countries in the world that have the best solar deposits; this solar energy is available on a large part of Algeria. The solar energy is a source of energy that can replace fossil energy because it is non-polluting and non-exhaustible. For the development of many solar energy devices and for the creation of performance estimates, it is necessary to know precisely the distribution of solar radiation in Algeria. Most African countries do not have the equipment and techniques to measure solar radiation. This is why we have developed methods for estimating solar radiation on the basis of meteorological data.

Several authors have developed models for estimating solar radiation. For the Arab world, Alnaser et al. [1] defused the atlas of solar radiation. In the latter, we find the duration of sunshine, global solar radiation and diffuse solar radiation. It covers 19 Arab States and almost 280 covering latitudes ranging from $0^{\circ}$ (tropical) to $37^{\circ} \mathrm{N}$ and longitudes ranging from $19^{\circ} \mathrm{E}$ to nearly $60^{\circ} \mathrm{E}$ at different altitudes relative to sea level. Used Artificial Intelligence (ANN) to develop a forecasting model that can estimate monthly average daily solar irradiance on a horizontal surface for locations in Uganda on the basis of meteorological station data [2]. Estimated average daily solar radiation using a model based on particle swarm optimizations and artificial neural networks [3]. The inputs of this model are: sunshine duration, latitude, longitude and altitude, the average monthly of the global solar radiation is the output.

In this year, we find several researchers working in the field of solar radiation; this is due to the interest of the latter in our daily life. Several experimental studies took place. Some researchers [4-9] have used solar radiation as an energy source to collect solar energy because solar radiation has a significant impact on the thermal efficiency of solar collectors. Some works were used the different meteorologic parameters such as humidity, temperature, pressure, and angle of sun elevation for determined the global solar radiation [10-14].

\section{PREDICTION OF THE SOLAR RADIATION}

In this point, we try to divide the map of Algeria between the coordinates of longitude and latitude by $-8.5^{\circ}$ West at $11.5^{\circ}$ East and $18.5^{\circ}$ North at $37.5^{\circ}$ South respectively for reason to update all the surface of Algeria with average solar radiation for create a matrix of database which help us to modeling numerically because this away to prediction the solar radiation as a function of the latitude and longitude coordinates.

Firstly, we try to prediction the average solar radiation as a function to latitude and secondly as a function to longitude which gives us the relationship:

$$
\begin{array}{ll}
E(L)=301.02-1.5 L-0.073 L^{2} & R^{2}=0.955 \\
E(\varphi)=597.21-24.48 \varphi+0.369 \varphi^{2} & R^{2}=0.833
\end{array}
$$

\section{ALGERIA LOCATION}

Algeria has the highest technical and economic potential for solar power exploitation in the MENA region, with about 170 TWh per year. First industrial scale solar thermal power project has been initiated by inauguration of Hassi R'Mel power station in 2011. This new hybrid power plant combines a 25-megawatt (MW) concentrating solar power array in conjunction with a $130 \mathrm{MW}$ combined cycle gas turbine plant. 


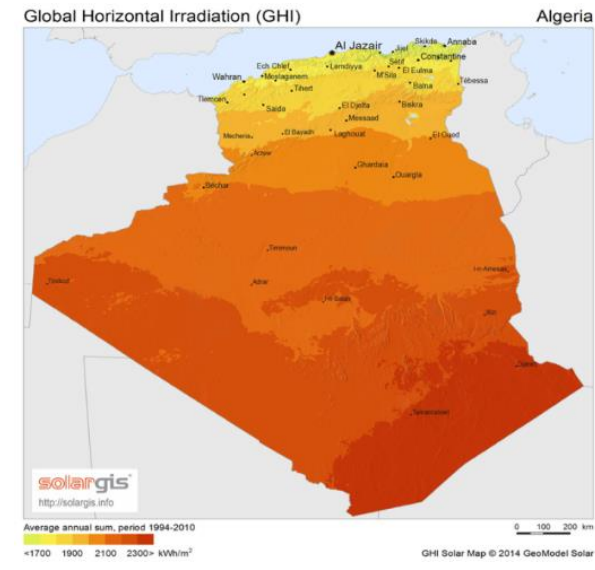

Figure 1. Algeria of global irradiation [15]

\section{RESULT AND DISCUSSION}

The Figure 2, show the variation of the solar radiation map according to coordinates latitude and longitude, we can be seen that the maximum solar radiation situated in the south Algeria with height large, range between the latitude $18.5^{\circ}$ and $23.5^{\circ}$, longitude $-8.5^{\circ}$ and $8.5^{\circ}$ by solar radiation same both $316.71 \mathrm{~W} / \mathrm{m}^{2}$ and $341.5 \mathrm{~W} / \mathrm{m}^{2}$, respectively, then with low solar radiation in the center of Algeria between $25^{\circ}$ and $32.5^{\circ}$ of the latitude that's mean the solar radiation depending to latitude coordinate meaning when go to equator, we noted that variation sensitive in this away.

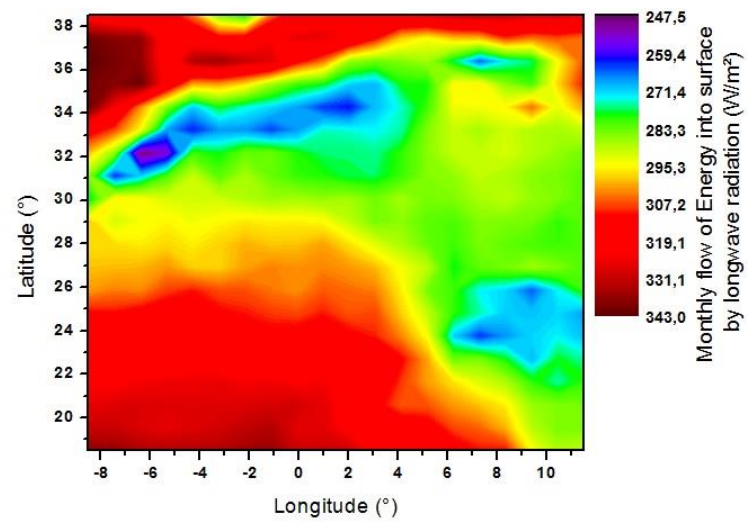

Figure 2. Variation of the solar radiation map according to coordinates latitude and longitude

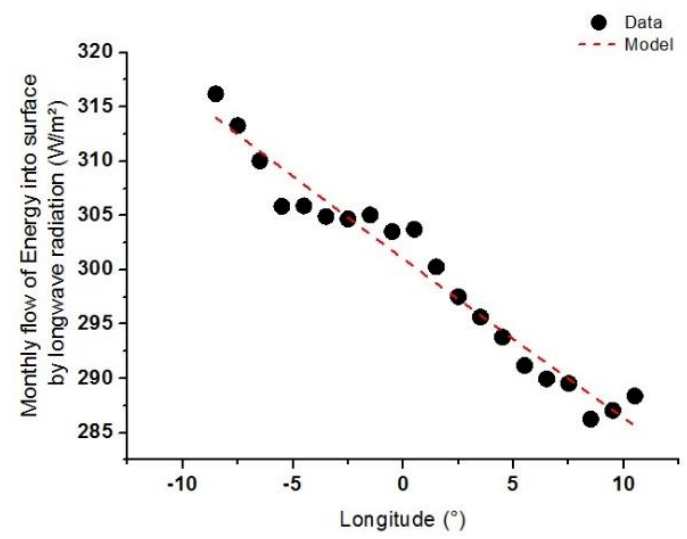

Figure 3. Variation of the solar radiation according to Longitude coordinate
Figure 3 show the solar radiation as a function to longitude coordinate, we can remark that evolution start with height value of solar radiation in the point of longitude coordinate equal to $-8.5^{\circ}$ and then takes a descries to a minimum value of solar radiation by $285 \mathrm{~W} / \mathrm{m}^{2}$ in the $10.5^{\circ}$.

The established model is taking a good away with a data of the solar radiation that's mean with low errors.

$$
\begin{aligned}
& E(L)=301.02-1.5 L-0.073 L^{2} \quad R^{2}=0.955 \\
& E(\varphi)=597.21-24.48 \varphi+0.369 \varphi^{2} \quad R^{2}=0.833
\end{aligned}
$$

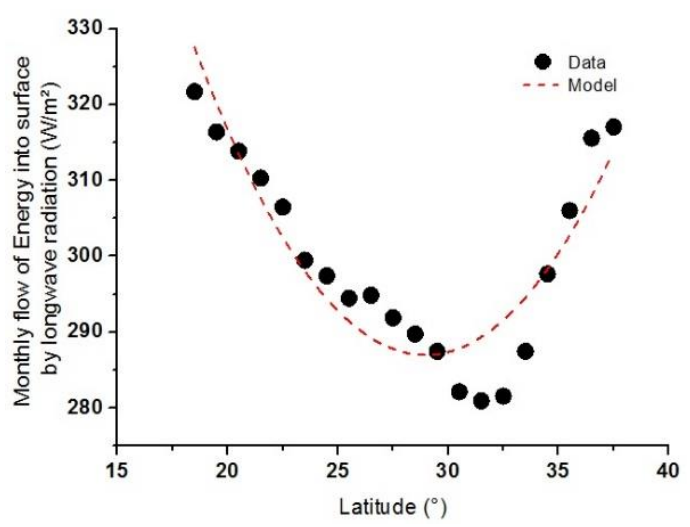

Figure 4. Variation of the solar radiation according to Latitude coordinate

Figure 4 show the solar radiation as a function to Latitude coordinate, we can remark that evolution start with height value of solar radiation in the two points of latitude coordinate limited in the extremity both 19.5 and $37.5^{\circ}$, then takes a descries to a minimum value in the low curves with peak of solar radiation in the latitude point same to $32.5^{\circ}$. The established model is taking a good away with a data of the solar radiation that's mean with low errors.

\section{CONCLUSIONS}

The purpose of this study is to develop a model for measuring the average solar irradiation as a function to coordinates of latitude and longitude on the map of Algeria. We conclude that the maximum solar radiation is located in southern Algeria with a high height, lies between latitude $18.5^{\circ}$ and $23.5^{\circ}$, longitude $-8.5^{\circ}$ and $8.5^{\circ}$, respectively, then with a weak solar radiation in the center of Algeria between $25^{\circ}$ and $32,5^{\circ}$ of latitude that is to say the solar radiation depending on the coordinate of latitude signifying when one goes to the equator.

The established model has given us the best approach with a small error, we can also predict solar radiation easily according to latitude and longitude coordinates.

\section{REFERENCES}

[1] Alnaser, W.E., Eliagoubi, B., Al-Kalak, A., Trabelsi, H., Al-Maalej, M., El-Sayed, H.M., Alloush, M. (2004). First solar radiation atlas for the Arab world. Renewable energy, 29(7): 1085-1107. 
[2] Mubiru, J., Banda, E.J.K.B. (2008). Estimation of monthly average daily global solar irradiation using artificial neural networks. Solar Energy, 82(2): 181-187. https://doi.org/10.1016/j.solener.2007.06.003

[3] Mohandes, M.A. (2012). Modeling global solar radiation using Particle Swarm Optimization (PSO). Solar Energy, 86(11): $3137-3145$ https://doi.org/10.1016/j.solener.2012.08.005

[4] Moummi, N., Chabane, F., Benramache, S., Brima, A. (2013). Thermal efficiency analysis of a single-flow solar air heater with different mass flow rates in a smooth plate. Frontiers in Heat and Mass Transfer (FHMT), 4(1).

[5] Chabane, F., Moummi, N., Benramache, S., Bensahal, D., Belahssen, O. (2013). Effect of artificial roughness on heat transfer in a solar air heater. Journal of Science and Engineering, 1(2): 85-93.

[6] Chabane, F., Moummi, N., Benramache, S. (2013). Experimental analysis on thermal performance of a solar air collector with longitudinal fins in a region of Biskra, Algeria. Journal of Power Technologies, 93(1): 52-58.

[7] Chabane, F., Moummi, N., Benramache, S., Bensahal, D., Belahssen, O., Lemmadi, F.Z. (2013). Thermal performance optimization of a flat plate solar air heater. International Journal of Energy \& Technology, 5(8): 1-6. https://doi.org/10.1016/j.apenergy.2009.10.015

[8] Chabane, F., Moummi, N., Benramache, S. (2012). Experimental study on heat transfer for a solar air heater and contribution the fins to improve the thermal efficiency. Int J Adv Renew Energ Res, 1: 487-494.
[9] Chabane, F., Moummi, N., Benramache, S. (2012). Experimental performance of solar air heater with internal fins inferior an absorber plate: in the region of Biskra. Int J Energ and Tech, 4(33): 1-6.

[10] Chabane, F., Guellai, F., Michraoui, M.Y., Bensahal, D., Bima, A., Moummi, N. (2019). Prediction of the Global Solar Radiation on Inclined Area. Applied Solar Energy, 55(1):

41-47. https://doi.org/10.3103/S0003701X19010055

[11] Chabane, F., Khadraoui, Z., Bensahal, D. (2018). Prediction of global solar radiation on the horizontal area with the effect of ambient temperature Part: II. Tecnica Italiana-Italian Journal of Engineering Science, 63: 7377.

[12] Chabane, F., Laznek, I., Bensahal, D. (2018). Prediction of global solar radiation on the horizontal area with the effect of relative humidity. Part: I. Italian Journal of Engineering Science: Tecnica Italiana, 61(2): 115-18. https://doi.org/10.18280/ti-ijes.620209

[13] Chabane, F., Ghedhifi, M. A., Bensahal, D., Brima, A., Moummi, N. (2018). Forecast of global solar irradiation with a perfect model according to incline angle. Journal of Power Technologies, 98(3): 245-254.

[14] Chabane, F., Moummi, N., \& Brima, A. (2016). Predictions of solar radiation distribution: Global, direct and diffuse light on horizontal surface. The European Physical Journal Plus, 131(4): 1-8. https://doi.org/10.1140/epjp/i2016-16106-7

[15] http:// Solargis.info Algeria Wikipedia 